\title{
Real-time sleep apnea detection using wavelet packet transform and support vector machines
}

\section{Type of article: conference Abstract}

\author{
Hadj Abd el Kader BENGHENIA, Zine-eddine HADJ SLIMANE
}

Département d'Electronique Biomédicale, Faculté des Sciences de l'Ingénieur, Université Abou bekr Belkaid, BP230-13000 Chetouane Tlemcen, Algérie benaek29@yahoo.fr, hadjslim@yahoo.fr

\begin{abstract}
Sleep apnea events as obstructive, central, mixed, or hypopnea are characterized by frequent breathing cessations or reduction in upper airflow during sleep. An advanced method for analyzing the patterning of biomedical signals to recognize obstructive sleep apnea and hypopnea is presented. In the aim to extract characteristic parameters, which will be used for classifying the above-stated (obstructive, central, mixed) sleep apnea and hypopnea, the proposed method is based, first, on the analysis of polysomnopraphy signals such as electrocardiogram signal (ECG) and electromyogram (EMG) and then classification of (obstructive, central, mixed) sleep apnea and hypopnea. The analysis is carried out using the wavelet transform technique in order to extract characteristic parameters, whereas classification is carried out by applying the SVM (support vector machine) technique. The obtained results show good recognition rates using characteristic parameters.
\end{abstract}

Keywords: Obstructive; central; mixed; sleep apnea; hypopnea; ECG; EMG; Wavelet transform; SVM classifier.

\section{Declaration of conflicts}

This article was selected from ICHSMT'16 abstract book.

\section{Authors' biography}

No Biography

3. References

No reference 